\title{
Presidential Symposium
}

\section{Clinical/Therapeutic: Presidential Symposium: Investing Early in Mental Health Pays Off Later in Life}

\section{PS001}

\section{Perinatal TOTAL Health}

\section{E. Sorel}

Professor of Global Health, Health Policy E Management and of Psychiatry and Behavioral Sciences, George Washington University, Washington- DC, USA

Introduction.- The perinatal period and the first thousand days of life are consequential for whole life TOTAL Health.

The $1^{\text {st }}$ International Perinatal TOTAL Health Congress: The First Thousand Days of Life was held in Sinaia, Romania in June 2018. It addressed the challenges and opportunities of this crucial period of life starting with preconception, intrauterine period, partum, postpartum, the first thousand days of life and their health consequences for the rest of life.

Objectives.- Scientific knowledge regarding the perinatal, intrauterine, and the first thousand days of life is rapidly evolving. We now have a better understanding of the systemic feedback loops between, mother, fetus, infant and environmental health as well as the catalytic transactions between the brain, genes, microbiome and immune system. Will address the current perinatal health scientific evidence, its relevance to the first thousand days of life, for whole life TOTAL Health and for health promotion, protection and illness prevention.

Method.- The presentation will be based on scientific evidence derived from the relevant, contemporary scientific literature inclusive of that presented from the $1^{\text {st }}$ International Perinatal TOTAL Health congress.

Results.- The baby brain connectome development, the mother's microbiome, immune system, nutrition and state of health/mental health are intrinsically affecting one another with remarkable impact on fetal and infant development. They impact the intrauterine development, the first thousand days of life, as well as with lifelong TOTAL health consequences.

Conclusions.- These new sources of scientific evidence are enriching our perinatal body of knowledge with new research vistas as well with significant implications for new research, training, health protection, promotion, illness prevention and care as well as inspiring new health policies [references 1-4].

References.-
[1] Van Essen, D.C., Smith, S.M., Barch, D.M., Behrens, T.E., Yacoub, E., Ugurbil, K., W.U.-M.H. Consortium, The WU-Minn Human Connectome Project: an overview, Neuroimage, 80 (2013) 62-79.

[2] Marmot, M., The Health Gap: The Challenge of an Unequal World, Bloomsbury Publishing, London \& NY 2015.

[3] Sorel, E. TOTAL Health for All in the $21^{\text {st }}$ Century, in Dignity in Mental Health, World Federation for Mental Health, Occoquan, VA 2015.

[4] Sorel, E., Raney, L., Integrated Care, Position Statement, American Psychiatric Association, Washington DC July 2016.

Disclosure of interest.- The authors have not supplied a conflict of interest statement.

\section{Clinical/Therapeutic: Presidential Symposium: Investing Early in Mental Health Pays Off Later in Life}

\section{PSO02}

\section{Improving mental health by targeting early life Epochs in Asia}

A. Javed

Pakistan Psychiatric Research Centre, Psychiatry, Lahore, United Kingdom

There is an emerging evidence that every year up to $30 \%$ of the population worldwide will suffer from some form of mental disorder, and at least two-thirds of those receive inadequate or no treatment, even in countries with the best resources. Asia, where most of the world population lives, presents with a very diverse picture. Variations in resources, availability of services, number of mental health professionals and absence of national policies for mental health are the salient features of status of psychiatry in many Asian countries. Most of these countries allocate very scarce financial resources and grossly inadequate work force $\&$ infrastructure for mental health provides further limitations in the mental health care systems. Despite the growing evidence about the impact of mental illnesses, mental health services continue showing big gaps. Even the current radical changes in organization, financing, treatment technology, and consumer demand for access and delivery of health services are not showing any big influence on the mental health scene in many countries. There are clear differences in the practice of psychiatry around the Globe but the low income and developing countries witness visible gaps in many areas of mental health care. Less number 
of mental health professionals, scarcity of mental health resources \& now often facing additional problems of migration of trained psychiatrists and mental health professionals to the already resource rich countries, the situation gets even worse.

This paper will present an overview about the mantel health gaps and their impact on the delivery of services with a special focus on the developing countries in Asian region. It will be argued that there is no health without mental health and Innovation, networking and basic training as well as better models of care using simple but effective paradigms need to be put in place if these countries are to provide better health services.

Disclosure of interest.- The authors have not supplied a conflict of interest statement.

\section{Mental Health Policy: Presidential Symposium: Violence and Discrimination in Women with Disabilities}

\section{PS003}

\section{Ethnic discrimination and women's mental health}

M. Schouler-Ocak

Psychiatric University Clinic of Charité at St. Hedwig Hospital Berlin, Psychiatry and Psychotherapy, Berlin, Germany
Discrimination is multidimensional, and its assessment should provide comprehensive coverage of all relevant domains. The most commonly assessed types of stressful experiences are life events, chronic stress, and daily hassles, all have their analogues among existing measures of discrimination. Life events are discrete, observable stressors. Chronic stressors are ongoing problems that are often role related and "Daily hassles" refers to chronic or episodic irritations that are minor. Major acute experiences of racial bias are the most commonly assessed type of discriminatory experience. Perceptions of discrimination appear to induce physiological and psychological arousal, and, as is the case with other psychosocial stressors, systematic exposure to experiences of discrimination may have long-term consequences for health. These experiences are part of the social and psychological context in which disease risk emerges and within which effective interventions to improve health must be embedded. In this lien, it is impressive that perceptions of discrimination tend to be associated with poorer health across a broad range of outcomes and across socially disadvantaged groups in different societies. Within this talk an overview of ethnic discrimination and women's mental health will be undertaken. Additionally, results about perceived discrimination from a crosssectional representative study on female refugees will be presented and discussed. 